\title{
Efficacy of occlusion for strabismic amblyopia: can an optimal duration be identified?
}

\author{
Marie Cleary
}

\begin{abstract}
Backgroundlaims-The study of occlusion efficacy in amblyopia has been hampered by the use of non-logMAR acuity tests and a failure to assess threshold acuity for both eyes. These issues are addressed in the current study which compares the effect of spectacles alone and spectacles in combination with occlusion, with the use of the $\log M A R$ crowded test.

Methods-Changes in uniocular and interocular acuity differences were compared for two age matched groups of previously untreated children with strabismic amblyopia: one compliant with spectacles only ( $\mathrm{n}=17$, mean 6.2 (SD 2.5) years) and the other with spectacles and occlusion ( $n$ $=69$, mean 5.1 (1) years) over a 1 year period. Changes in $\log$ MAR acuity were also analysed for a larger occluded group $(\mathbf{n}=119)$ in response to successive 200 hour blocks of occlusion up to $\geqslant 1000$ hours, in an attempt to isolate an optimal occlusion regime.

Results-Visual acuity improved for more of the amblyopic eyes of the occluded $(74 \%)$ than the spectacles only group (59\%), and only one child from the latter group deteriorated. Mean visual acuity improved for both eyes of both treatment groups, but the change was significantly larger for the strabismic eyes of the occluded group overall and within the first 6 month period $(p<0.05)$. Occlusion was only effective for the first 400 hours worn. Subsequent visual improvement was bilateral and symmetrical.
\end{abstract}

25 August 1999

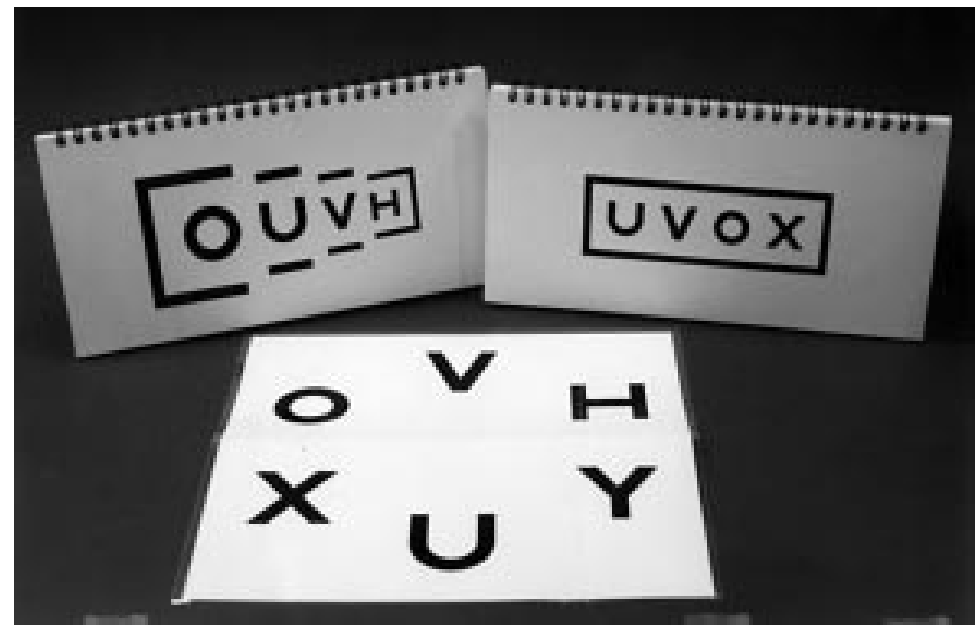

Figure 1 Logmar crowded test (Glasgow acuity cards).
Conclusion-Occlusion is more effective in the treatment of strabismic amblyopia than spectacles alone, and the effect is optimal within the first 6 months of wear. In terms of occlusion duration, maximal improvement occurs in response to 400 hours of occlusion wear or less, and to full time occlusion. Visual maturation continues, but is retarded for amblyopic eyes. (Br f Ophthalmol 2000;84:572-578)

Amblyopia affects $2-3 \%$ of the population, and strabismus, often associated with anisometropia, is a major cause. ${ }^{1}$ Diagnosis is based on reduced visual acuity, ${ }^{2}$ but other anomalies such as reduced contrast sensitivity ${ }^{4}$ and anomalous spatial sense frequently co-exist. ${ }^{56}$ Eccentric fixation is manifest in up to $80 \%$ of amblyopes ${ }^{7-9}$ and this, along with other fixation anomalies, ${ }^{10}$ contributes to the visual acuity reduction. Occlusion of the non-amblyopic eye remains the mainstay of treatment, ${ }^{11-13}$ but the efficacy of occlusion treatment is poorly quantified, and the validity of this form of treatment has recently been questioned because of a lack of randomised controlled trials. ${ }^{14}$ Inconsistencies in the literature further cloud the issue, with a successful visual outcome being variously defined as $6 / 9,{ }^{15}$ $6 / 12,{ }^{16}$ and $6 / 18,{ }^{17}$ and the mode of visual assessment varying throughout follow up. ${ }^{15-17}$

Accurate monitoring of the occlusion compliance is a prerequisite for the assessment of treatment efficacy. ${ }^{18}{ }^{19}$ A skin sensitive "intelligent" patch facilitates such monitoring, ${ }^{20}$ but this is currently not financially viable, and a parental diary system has compared favourably with this apparatus. ${ }^{21} 22$ Standardisation of paediatric visual acuity testing is fundamental to the determination of occlusion efficacy, with an optimal test combining an equivalent degree of crowding for each line, equal step sizes, and the ability to assess threshold in all cases (logMAR crowded test) (Fig 1). Consideration should also be given to the normal maturation of visual acuity. ${ }^{23} 24$

The visual improvement manifested by many occluded cases ${ }^{11}{ }^{24}$ has hitherto, presented an ethical dilemma, precluding randomised controlled clinical trials of occlusion efficacy. A poorer outcome in untreated cases in a cross sectional study, ${ }^{25}$ and a lack of improvement or visual deterioration in noncompliant children followed longitudinally add to this dilemma. ${ }^{26}$

While the optimum daily and total "dose" of occlusion have not been defined, maximum visual recovery in the amblyopic eye probably 
Table 1 Characteristics of groups $A, A 1$, and B: A1 and B compared by means of an unpaired Student's t test, Mann-Whitney $U$ test, and the $\chi^{2}$ test

\begin{tabular}{|c|c|c|c|c|c|c|}
\hline Characteristic & Category & Group $A(n=119)$ & Group $A 1(n=69)$ & Group B $(n=17)$ & $t / Z / \chi^{2}$ & $p$ Value \\
\hline \multirow[t]{2}{*}{ Age (months) } & mean $(\mathrm{SD})$ & $61(13)$ & $61(12)$ & $74(30)$ & $Z-0.92$ & 0.36 \\
\hline & median & 58 & 58 & 57 & & \\
\hline \multirow[t]{4}{*}{ SER (dioptres) } & & & & & df 74 & \\
\hline & Strabismic & $4.0(2.1)$ & $4.2(1.9)$ & $3.8(2.4)$ & t 0.95 & 0.35 \\
\hline & Dominant & $2.9(1.8)$ & $2.8(1.7)$ & $3.1(2.1)$ & t 0.73 & 0.47 \\
\hline & Interoc dif & $0.9(1.5)$ & $1.1(1.7)$ & $0.5(0.8)$ & $\mathrm{t}-0.57$ & 0.57 \\
\hline \multirow[t]{2}{*}{ Amblyopia category } & Strabismic & $\mathrm{n}=65$ & $\mathrm{n}=34$ & $\mathrm{n}=12$ & df 1 & \\
\hline & Mixed & $\mathrm{n}=54$ & $\mathrm{n}=35$ & $\mathrm{n}=5$ & $\chi^{2} 1.65$ & 0.20 \\
\hline \multirow[t]{2}{*}{ Strabismus category } & Esotropia & $\mathrm{n}=100$ & $\mathrm{n}=59$ & $\mathrm{n}=15$ & $\mathrm{df} 1$ & \\
\hline & Exotropia & $\mathrm{n}=19$ & $\mathrm{n}=10$ & $\mathrm{n}=2$ & $\chi^{2} 0.001$ & 0.97 \\
\hline \multirow[t]{2}{*}{ BSV } & BSV & 49 abnormal & 37 abnormal & 6 abnormal & df 1 & \\
\hline & suppression & $\begin{array}{l}64 \text { suppression } \\
6 \text { inconclusive }\end{array}$ & 32 suppression & 11 suppression & $\chi^{2} 0.14$ & 0.52 \\
\hline Fixation & Eccentric & 90 eccentric & 52 eccentric & 11 eccentric & df 1 & \\
\hline & Foveal & 29 foveal & 17 foveal & 6 foveal & $\chi^{2} 3.62$ & 0.16 \\
\hline \multirow[t]{4}{*}{ First corrected GAC score (log units) mean (SD) } & & & & & df 74 & \\
\hline & Strabismic & $0.448(0.272)$ & $0.431(0.253)$ & $0.504(0.249)$ & $\mathrm{t}-0.68$ & 0.50 \\
\hline & Dominant & $0.903(0.141)$ & $0.898(0.118)$ & $0.922(0.162)$ & t 0.69 & 0.49 \\
\hline & Interoc dif & $0.456(0.263)$ & $0.467(0.241)$ & $0.418(0.351)$ & $\mathrm{t}-1.45$ & 0.15 \\
\hline
\end{tabular}

$\mathrm{t}=$ two tail unpaired Student's $t$ test, applied for interval data which follows a normal distribution.

$\mathrm{Z}=$ Mann-Whitney $\mathrm{U}$ test, non-parametric version of $t$ test applied to interval data with a non-normal distribution.

$\chi^{2}=$ data categorised by dichotomous scale.

$\mathrm{df}=$ degrees of freedom.

Interoc dif $=$ interocular difference.

$\mathrm{BSV}=$ binocular single vision; $\mathrm{SER}=$ spherical equivalent refraction

occurs within the first 3 months of occlusion..$^{27} 28$

The primary aim of the present longitudinal study was to compare prospectively the influence of occlusion and spectacles on $\log$ MAR visual acuity in children newly diagnosed as strabismic and mixed amblyopes (strabismic and anisometropia of $\geqslant 1$ dioptre spherical equivalent refraction). The secondary aim was to determine an optimal occlusion regime, and to consider the factors which influence response to occlusion.

\section{Methods}

A cohort of 136 children with either strabismic $(\mathrm{n}=77)$ or mixed amblyopia $(\mathrm{n}=59)$ were identified from 3847 new referrals presenting to our department over a 3.5 year period between June 1993 to December 1996. Patients with purely refractive amblyopia, a history of previous treatment, lack of compliance with spectacle wear (less than $75 \%$ wearing time), lack of follow up data because of non-attendance, or organic amblyopia were not included.

Of the 136 children prescribed occlusion and followed longitudinally, 119 complied with occlusion (group A) and the other 17 failed completely to comply with occlusion (0 hours), (group B). In comparing the influence of spectacles alone versus occlusion and spectacles, only those followed for at least 1 year were included. This encompassed all of group B ( $=17$ ) and 69 children from group A (referred to as group A1). While the study was not randomised and controlled, the groups were comparable on the basis of all of the variables generally considered as potentially influencing response to treatment (see Table 1), thus reducing the number of potential variables. Visual acuity was assessed with the logMAR crowded test, ${ }^{29}$ previously known as the Glasgow acuity cards (GAC), a paediatric test which permits the assessment of crowded threshold acuity. The score is represented by 1 minus the $\log$ of the minimum angle of resolu- tion (MAR), so a higher score denotes a better acuity level. Amblyopia is defined for the purpose of this study as a uniocular GAC score of $\leqslant 0.725 \mathrm{log}$ units or an interocular difference of $\geqslant 0.1 \mathrm{log}$ unit with GAC. ${ }^{30}$ Amblyopia was diagnosed only after $6-10$ weeks of full time spectacle wear. A significant change was considered to be $\geqslant 0.125 \log$ units $^{31}$ - that is, one line plus one letter or more (four letters per line, each with a value of $0.025 \mathrm{log}$ units).

A full spectacle correction was prescribed in all cases on the basis of a cycloplegic refraction (cyclopentolate hydrochloride $1 \%$ for $20-40$ minutes).

A comprehensive orthoptic assessment at each visit included detailed fixation assessment by visuscopy, ${ }^{32}$ and assessment of suppression density in children of 6 and over to monitor the risk of insuperable diplopia.

Following the initial period with spectacles, changes in visual acuity (strabismic and dominant eyes and interocular acuity differences) were compared at 3 monthly intervals up to 12 months for groups A1 and B, by means of an unpaired two tailed Student's $t$ test. Only those children from group A1 who were undergoing occlusion at each time interval were included.

In looking for an optimal occlusion regime changes in visual acuity for each eye were compared for the whole occluded group (A, n = 119) in response to consecutive 200 hour periods of occlusion worn up to a total of $\geqslant 1000$ hours. The influence of full time ( $\geqslant 8$ hours daily: $8-12$ hours prescribed) and part time wear ( $\leqslant 7$ hours: $2-6$ hours prescribed) were also compared, and the effect of other potential variables considered.

Part time occlusion was the sole treatment worn by most of group A ( $\mathrm{n}=73,61 \%)$, with the other 46 children (39\%) wearing a period of full time occlusion. For the purpose of analysis, Blenderm $(3 M)(n=22)$ and atropine $(\mathrm{n}=3)$ were grouped as full time occlusion. Occlusion was worn for an average of 8 (SD 6) months, and for a mean of 778 (711) hours (mean daily dosage 3.7 (3.3) hours). For chil- 


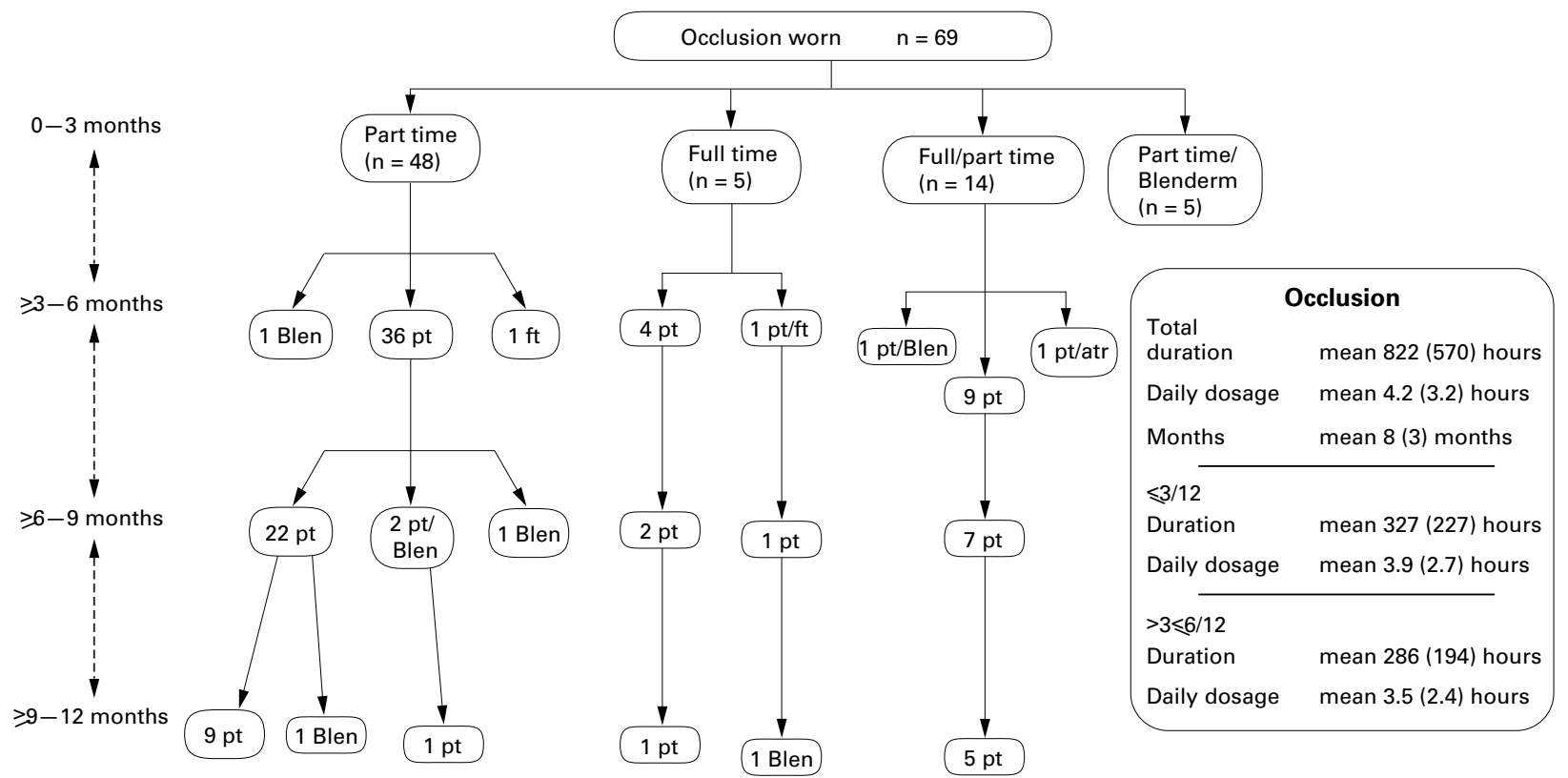

Figure 2 Flow diagram of occlusion at 3 monthly intervals for group $A 1(n=69) . f t=$ Full time, $p t=$ part time, Blen $=$ Blenderm, atr $=$ atropine .

dren compliant with full time occlusion the mean daily dosage was 9.6 (1.8) hours, and for those who wore part time only, 3.1 (1.8) hours. Two hundred hours of occlusion were, on average, accumulated over 2 months (worn 3-4 hours daily), with a range of 17 days (12 hours daily) to 200 days (1 hour daily).

The mean occlusion duration and daily dosage for group A1 was similar to that for group A (Fig 2). The occlusion regime was primarily based on the degree of amblyopia, although individual flexibility was applied in order to promote compliance, and individual orthoptist preference played a role. Full time occlusion was avoided in school age children with dense amblyopia $(\leqslant 0.3 \mathrm{log}$ units in the strabismic eye) to avoid disruption of school work, and in cases of a low density of suppression or reduced fusional reserves, to avoid the risk of insuperable diplopia. Close work was encouraged during patching, particularly at school or nursery. Occlusion dosage was either reduced then stopped when visual acuity plateaued over 2-3 months despite reported good compliance, or increased to full time total or Blenderm in an attempt to improve outcome. Initial follow up was at 2-6 weeks, and at 2-10 weeks intervals thereafter, with full time wearers reviewed at shorter intervals, to monitor the risk of occlusion amblyopia ${ }^{33}$ and insuperable diplopia.

All children in group A were followed for 6 months or more, and $69(58 \%)$ for a year or more. Parents were asked to judge compliance with spectacle wear as falling into one of four categories: full time $(100 \%)$; most of time $(\sim 75 \%)$; half of time $(50 \%)$; poor $(<50 \%)$. Parents were also asked to monitor the number of hours occlusion worn per day, allowing a mean daily dosage to be calculated. The total was calculated as a percentage of that prescribed. Mean compliance for group A was $74 \%$ $(28 \%)$, with poor compliance $(<50 \%)$ in only
$20 \%$ of cases. Follow up after cessation of occlusion was for a mean of 10 (SD 9) months.

\section{Results}

COMPARISON OF VA OUTCOMES FOR OCCLUDED $(\mathrm{A} 1, \mathrm{~N}=69)$ AND NON-OCCLUDED GROUPS (B, N $=17)$

Achievement of normal acuity (defined as a uniocular acuity of $\geqslant 0.750 \mathrm{log}$ units, and an interocular difference of $<0.1 \mathrm{log}$ units) was slightly more common for the occluded children $(29 \%)$ than for those who wore spectacles only $(20 \%)$. More of the strabismic eyes of the occluded children also improved than the spectacles only group ( $74 \%$ of $\mathrm{A} 1,59 \%$ of B), while similar proportions of the dominant eyes improved $(42 \%$ of $\mathrm{A} 1,41 \%$ of $\mathrm{B})$. Deterioration was rare, occurring for one dominant eye of each group and for the strabismic eye of only one child who wore spectacles only. Two of the occluded children had reduced acuity in the dominant eye before occlusion, which may be explained by a lack of cooperation with the VA test or overaccommodation with spectacles.

The improvement in visual acuity proved significant for both eyes of both groups for the 12 month period (Fig 3 and Table 2). This was also reflected in the reduction in interocular acuity difference for the occluded group $A 1$ (paired $t$ test $\mathrm{p}=0.004)$, but not for group B ( $\mathrm{p}$ $=0.57$ ). The outcome for the occluded group was also significantly better in terms of final visual acuity for the strabismic eyes (unpaired $t$ test $1.98, \mathrm{p}=0.05)$, and smaller interocular acuity difference (unpaired $t 2.12, \mathrm{p}=0.04$ ). The visual outcome for the dominant eyes was comparable $(p>0.05)$. All of these factors support the benefits of occlusion over spectacles only.

Visual improvement was maximal within the first 3 months of occlusion, and the change in both strabismic eye acuity and interocular difference was significantly larger for the oc- 


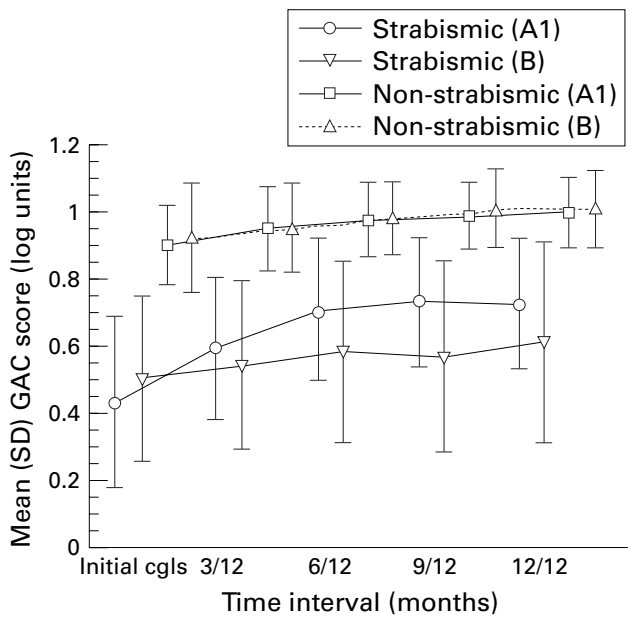

Figure 3 Mean GAC score for the strabismic and dominant eyes of groups $A 1(n=69)$ and $B(n=17)$ for 3 monthly intervals up to 12 months.

cluded than the spectacles group only up to 6 months $(p=0.008)$. The rate of change for the dominant eyes remained symmetrical throughout $(\mathrm{p}>0.05)$.

The influence of visual maturation was evident when VA for the dominant eyes of groups A1 and B were analysed collectively in relation to age at the initial visit with spectacles. The lower mean VA for children aged 6-7 years is likely to reflect the small group size for this age group:

- <4 years $(\mathrm{n}=4)$ mean $0.790(0.133) \log$ units;

- $>4 \leqslant 5$ years $(n=42)$ mean $0.885(0.116)$ $\log$ units;

- $>5 \leqslant 6$ years $(\mathrm{n}=22)$ mean $0.908(0.120)$ $\log$ units;

- $>6 \leqslant 7$ years $(n=7)$ mean $0.879(0.131) \log$ units;

- >7 years $(\mathrm{n}=10)$ mean $1.040(0.092) \log$ units.
The magnitude of change in visual acuity did not differ significantly for different age groups assessed by analysis of variance (ANOVA), or for individual time periods $(\mathrm{p}>0.05)$.

Since the numbers occluded diminished over the 12 month period, group characteristics were looked at for each time period to avoid variables which can influence outcome (Table 1). A transient increase in the relative proportion of anisometropes among the occluded group for the period at 9 months $(p=0.04)$ did not alter the mean strength of refractive error ( $\mathrm{p}>0.05)$. The groups, therefore, remained comparable throughout the follow up period.

INVESTIGATION OF OCCLUSION EFFICACY IN

RELATION TO DURATION WORN (GROUP A, N $=119$ ) There was an overall reduction in amblyopia prevalence by $18 \%$ ( $100 \%$ reduced to $82 \%$ ), with $37 \%$ of strabismic eyes and $17 \%$ of dominant eyes improving throughout the occlusion period. A gradual bilateral improvement was again evident (Fig 4), but the mean improvement was significantly larger for the strabismic than the dominant eyes for the two periods up to 400 hours (Table 3). A deterioration of 0.1 log units for one dominant eye of a 4 year old child (53 months) is likely to represent occlusion amblyopia rather than a lack of cooperation with the VA test since the fellow eye had improved by $0.2 \log$ units.

For 17 children (14\%), the strabismic eye regressed by $\geqslant 0.125 \mathrm{log}$ units on stopping occlusion, nine of whom had previously achieved normal visual acuity. Four children manifested a bilateral regression, which may reflect a refractive change or temporary poor compliance with spectacles or the VA test, although neither of the latter were reported. Amblyopia recurred in another three children who had achieved normal VA, based on an improvement in the VA of the dominant eye as opposed to a deterioration in the strabismic

Table 2 Mean change in GAC score at 3 monthly intervals for strabismic and dominant eyes and interocular acuity difference for groups $A 1$ and B, compared by unpaired Student's t test

\begin{tabular}{|c|c|c|c|c|c|c|c|}
\hline \multicolumn{2}{|l|}{$\begin{array}{l}\text { Time interval } \\
\text { (months) }\end{array}$} & \multicolumn{2}{|l|}{ Group A1 $(n=69)$} & \multirow{2}{*}{$\begin{array}{l}\text { Group B }(n=17) \\
\text { Strabismic }\end{array}$} & \multicolumn{3}{|c|}{ Statistics (unpaired t test) } \\
\hline & $n$ & Strabismic & & & $d f$ & $t$ & p Value \\
\hline Initial $-\leqslant 3$ & 69 & $0.223(0.165)$ & 17 & $0.038(0.063)$ & 84 & -4.51 & $0.0001^{\star}$ \\
\hline$>3-\leqslant 6$ & 54 & $0.094(0.106)$ & 17 & $0.044(0.090)$ & 69 & -1.76 & $0.008^{\star}$ \\
\hline$>6-\leqslant 9$ & 35 & $0.044(0.104)$ & 12 & $0.015(0.043)$ & 45 & -0.95 & 0.34 \\
\hline$>9-\leqslant 12$ & 18 & $0.019(0.115)$ & 12 & $0.004(0.037)$ & 28 & -0.44 & 0.66 \\
\hline Initial- $\leqslant 12$ & 18 & $0.471(0.264)$ & 17 & $0.104(0.127)$ & 33 & -5.18 & $0.0007^{\star}$ \\
\hline \multirow{3}{*}{$\begin{array}{l}\text { Change in } \\
\text { initial- } \leqslant 12, \\
\text { paired } t \text { test }\end{array}$} & df & $t-11.04$ & $\mathrm{df}$ & $t-3.38$ & & & \\
\hline & 68 & $\mathrm{p}=0.0001$ & 16 & $\mathrm{p}=0.004$ & & & \\
\hline & $n$ & Dominant & & Dominant & $d f$ & $t$ & $p$ Value \\
\hline Initial $-\leqslant 3$ & 69 & $0.043(0.081)$ & 17 & $0.028(0.051)$ & 84 & -0.734 & 0.47 \\
\hline$>3-\leqslant 6$ & 54 & $0.035(0.062)$ & 17 & $0.028(0.049)$ & 69 & -0.41 & 0.68 \\
\hline$>6-\leqslant 9$ & 35 & $0.007(0.085)$ & 12 & $0.023(0.043)$ & 45 & 0.61 & 0.54 \\
\hline$>9-\leqslant 12$ & 18 & $0.010(0.063)$ & 12 & $0.010(0.017)$ & 28 & 0.04 & 0.97 \\
\hline Initial- $\leqslant 12$ & 18 & $0.097(0.090)$ & 17 & $0.082(0.086)$ & 33 & -0.50 & 0.62 \\
\hline \multirow{3}{*}{$\begin{array}{l}\text { Change in } \\
\text { initial- } \leqslant 12, \\
\text { paired } t \text { test }\end{array}$} & $\mathrm{df}$ & $t-7.33$ & df & $t-3.93$ & & & \\
\hline & 68 & $\mathrm{p}=0.0001$ & 16 & $\mathrm{p}=0.001$ & & & \\
\hline & $n$ & Interocular difference & & Interocular difference & $d f$ & $t$ & $p$ Value \\
\hline Initial- $\leqslant 3$ & 69 & $-0.173(0.172)$ & 17 & $-0.010(0.078)$ & 84 & 3.79 & $0.0003^{\star}$ \\
\hline$>3-\leqslant 6$ & 54 & $-0.052(0.086)$ & 17 & $0.022(0.082)$ & 69 & 3.13 & $0.0003^{\star}$ \\
\hline$>6-\leqslant 9$ & 35 & $-0.035(0.153)$ & 12 & $-0.017(0.053)$ & 45 & 0.40 & 0.69 \\
\hline$>9-\leqslant 12$ & 18 & $-0.013(0.115)$ & 12 & $-0.006(0.040)$ & 28 & 0.18 & 0.86 \\
\hline Initial- $\leqslant 12$ & 18 & $-0.336(0.347)$ & 17 & $-0.022(0.155)$ & 33 & 3.42 & $0.002^{\star}$ \\
\hline \multirow{2}{*}{$\begin{array}{l}\text { Change in } \\
\text { initial- } \leqslant 12, \\
\text { paired } t \text { test }\end{array}$} & $\mathrm{df}$ & $t 8.56$ & df & $t 0.59$ & & & \\
\hline & 68 & $\mathrm{p}=0.0001$ & 16 & $\mathrm{p}=0.57$ & & & \\
\hline
\end{tabular}




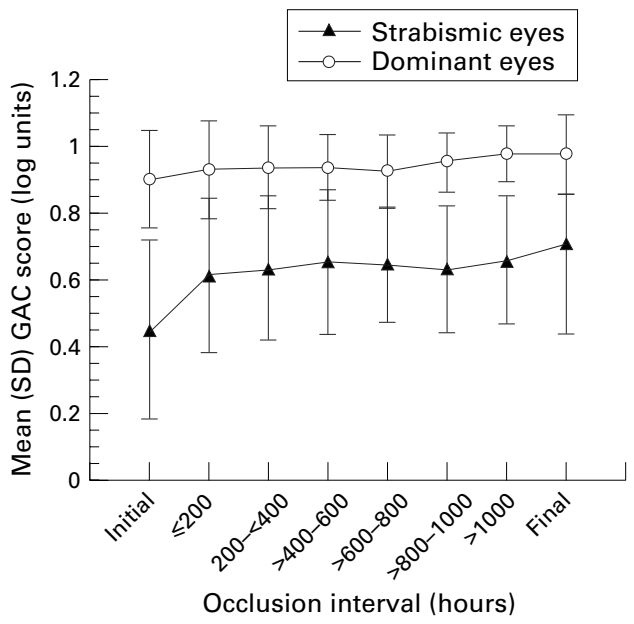

Figure 4 Mean (SD) GAC scores preocclusion, and for occlusion time intervals up to $>1000$ hours, and final acuity for strabismic/mixed amblyopes $(n=119)$.

eye. This suggests that the normal developmental processes are held in stasis for the strabismic eye, but continue for the dominant eye.

EVALUATION OF POTENTIAL VARIABLES

INFLUENCING OUTCOME (GROUP A, N = 119)

Comparing residual amblyopes with those who achieved "normal" VA (that is, a unilateral GAC score of $\geqslant 0.750 \log$ units and an interocular difference of $<0.1 \mathrm{log}$ units), many factors failed to influence outcome-namely, age at instigation of treatment, initial VA, percentage compliance with occlusion, and time to maximum visual acuity ( $p>0.05)$.

A higher proportion of purely strabismic amblyopes achieved "normal" VA (32\%) than mixed amblyopes (22\%), but the response to occlusion was not essentially different in terms of changes in strabismic eye VA and interocular acuity difference $(p>0.05)$. The tendency for more dense amblyopia among the mixed amblyopes (mixed 0.350 (0.245); strabismic 0.537 (0.262) log units) did, however, predispose towards a poorer outcome (mixed 0.616 (0.218); strabismic 0.736 (0.189) log units).

Eccentric fixation proved a barrier to achieving normal VA, with eccentric fixators $(n=62)$ manifesting a significantly lower strabismic eye GAC score and higher interocular acuity difference (Mann-Whitney $\mathrm{U}$ test $\mathrm{Z}-4.39, \mathrm{p}=$ $0.0001 ; Z-4.08, p=0.0001)$ than those with foveal fixation $(n=57)$. Visual acuity deteriorated with increasing degrees of eccentric fixation $(r=0.53, \mathrm{p}=0.0001)$.

Full time occlusion produced a greater improvement in visual acuity for the strabismic eyes $(t-1.97, \mathrm{p}=0.05)$ and reduction in inte-

Table 3 Comparison of the mean (SD) change in GAC score for the strabismic and dominant eyes for the six quantities of occlusion worn, by unpaired Student's t test $(n=119)$

\begin{tabular}{lllllll}
\hline Quantity of occlusion & $n$ & Strabismic eye & Dominant eye & $d f$ & $t$ Value & $p$ Value \\
\hline Initial to $\leqslant 200$ hours & 105 & $0.144(0.202)$ & $0.024(0.156)$ & 208 & -4.85 & $0.0001^{\star}$ \\
$>200$ to $\leqslant 400$ & 78 & $0.076(0.141)$ & $0.022(0.088)$ & 154 & -2.88 & $0.005^{\star}$ \\
$>400$ to $\leqslant 600$ & 55 & $0.051(0.151)$ & $0.016(0.089)$ & 108 & -1.48 & 0.14 \\
$>600$ to $\leqslant 800$ & 44 & $0.028(0.148)$ & $0.016(0.074)$ & 86 & -0.50 & 0.62 \\
$>800$ to $\leqslant 1000$ & 36 & $0.021(0.129)$ & $0.039(0.079)$ & 70 & 0.71 & 0.48 \\
$>1000$ & 36 & $0.007(0.006)$ & $0.010(0.083)$ & 70 & 0.41 & 0.68 \\
Post-occlusion to final & 119 & $0.013(0.056)$ & $-0.018(0.082)$ & 236 & 0.77 & 0.44 \\
\hline
\end{tabular}

${ }^{\star}$ Indicates significant at $5 \%$ level. rocular difference $(t 1.96, \mathrm{p}=0.05)$ than part time occlusion. This was also true for the period of occlusion from $>200$ to 400 hours (strabismic eyes $t-2.31, \mathrm{p}=0.02$; interocular acuity difference, $t 1.94, \mathrm{p}=0.06$ ), but not for the initial 200 hours of occlusion worn ( $\mathrm{p}$ $>0.05$ ).

The time to maximum VA was similar for both groups (residual amblyopes 19 (17) weeks; non-amblyopes: 16 (11) weeks), as was the duration of occlusion worn (residual amblyopes: mean 417 (345) hours; normal VA mean 485 (385) hours). This suggests that the residual amblyopes are unlikely to have benefited significantly from a further period of occlusion.

After stopping occlusion, the mean GAC score for the dominant eyes improved slightly while that for the strabismic eyes deteriorated slightly, but these changes were not statistically significant $(p>0.05)$.

\section{Discussion}

The greater improvement in $\log$ MAR acuity for the strabismic eyes of the occluded children than for the spectacles only group confirms the positive influence of occlusion as an effective amblyopia treatment. Maximal influence within the first 3 months of initiation of occlusion confirms previous reports ${ }^{27}{ }^{28}$ which have employed a variety of crowded and uncrowded non- $\log M A R$ acuity tests, but the influence extended to 6 months in the current study. This has clinical implications for the management of strabismic amblyopia, in terms of both cost and the motivational influence on patients and parents. Occlusion may be prolonged unnecessarily in many cases, which is borne out by the lack of difference in the time to achieve "normal" acuity and the time to maximum acuity for the residual amblyopes in the study. It would seem that if "normalisation" of visual acuity is not achieved in response to 6 months of occlusion, the prognosis for achieving this is poor.

The observed visual acuity improvement for the dominant eyes is likely to represent a response to correction of optical defocus in some cases, but as has been acknowledged this is unlikely to be the sole factor in those displaying continuing improvement, particularly with small refractive corrections. ${ }^{22}$ A training effect with the test is also probable in the early stages, but visual improvement for the dominant eye over an extended period is likely to represent the normal maturation of high contrast linear acuity, which involves anatomical, physiological, and cognitive changes. This was emphasised by assessment of threshold linear visual acuity with a $\log M A R$ crowded test throughout the study. Clearly the younger children had poorer GAC scores than the older children in the study group, and differences between visually normal children and adults has already been acknowledged. ${ }^{34}$ The rate of improvement did not differ for different age groups, although the numbers were skewed towards the age groups 5 and 6 years. This requires a larger study encompassing a wider age range, 
with equivalent numbers in each group, to be explored in more detail.

As in previous studies, age at initiation of treatment was not influential on outcome in the current study. ${ }^{1215}{ }^{28}$ All children were within the sensitive period of visual development which extends until at least 8 years of age. ${ }^{35} 36$

The optimal duration of 400 hours of occlusion equates with a relatively wide range of time, from 6 weeks to 6 months, depending on the daily dosage worn. While full time occlusion proved more effective for the period from $>200$ to 400 hours, the results were inconclusive in relation to the initial 200 hour period of occlusion wear. This area clearly requires further study, with precise monitoring of occlusion compliance.

Percentage compliance in itself did not influence efficacy in a major way, in contrast with previous reports, ${ }^{18}{ }^{19}$ although an effect is implicated by the superiority of full time occlusion over part time, and an optimal response to 400 hours of occlusion wear.

Coexistence of strabismus and anisometropia are known to constitute a barrier to the achievement of "normal" VA, ${ }^{17}{ }^{37}$ but the influence of occlusion on these amblyopic categories was not essentially different, although a tendency for more dense amblyopia equated with a poorer outcome.

Since normal retinocortical organisation dictates that the fovea has optimal visual acuity, with visual acuity dropping off sharply with increasing retinal eccentricity ${ }^{38}$ the poorer outcome in those with eccentric fixation is not surprising. Fixation has received little attention in recent clinical amblyopia studies, but clearly even small degrees of eccentric fixation remain a therapeutic challenge, ${ }^{24}$ therefore greater emphasis on treatment specifically targeted at this feature may improve the success rate of amblyopia therapy.

The number achieving normal VA in this study was poor in comparison with some other studies, ${ }^{15} 17$ 28-39 which have employed Snellen and single optotype tests, and in some cases included children with no quantified VA preocclusion. The amblyopia criterion of one line difference between the two eyes, and ability to assess the threshold for the $\log$ MAR crowded test, compared with non-logMAR tests, undoubtedly influenced this.

The natural history of amblyopia is relatively unknown, although recent reports suggest visual acuity deteriorates without intervention. ${ }^{25} 26$ This was borne out in only one child in the current study, therefore deterioration is not inevitable without occlusion treatment. ${ }^{24}$

It is acknowledged that this study is not randomly controlled, and this is a future aim, but the results strongly support occlusion as a beneficial therapy in amblyopia. The influence is maximal during the first 400 hours worn, and within the first 3-6 months of occlusion treatment. A number of other factors may influence the change in VA beyond this time period. The visual system is flexible in childhood and developmental factors are likely to have a significant influence on the changes in visual acuity observed. Optical correction, occlusion wear, and visual maturation all played a part in visual acuity improvement in the study group, but normal maturational processes were disrupted for the strabismic eyes. The use of logMAR acuity cards is strongly recommended as an accurate means of assessing threshold acuity in children. This allows improvement in the dominant eye to be monitored, thus avoiding misinterpretation of change in the amblyopic eye as a treatment effect as opposed to visual maturation.

I would like to express my sincere gratitude to Professor Gordon $\mathrm{N}$ Dutton for his invaluable comments on the manuscript, and his continual support and encouragement.

1 Flynn JT, Cassady JC. Current trends in amblyopia therapy. Ophthalmology 1978;85:428-50.

2 Abrahamsson M, Sjöstrand J. Contrast sensitivity and acuity relationship in strabismic and anisometropic amblyopia. $\mathrm{Br}$ f Ophthalmol 1988;72:44-9.

3 Hess RF, Howell ER. The threshold contrast sensitivity function in strabismic amblyopia: evidence for a two-type function in strabismic amblyopia: eviden
classification. Vis Res 1977;17:1049-54.

4 Giaschi GE, Regan D, Kraft SP, et al. Crowding and contrast in amblyopia. Optom Vis Sci 1993;70:192-7.

5 Flom MC, Bedell LE. Identifying amblyopia using associated conditions: acuity and non-acuity features. $A m \mathcal{F}$ Optom Phys Optics 1985;62:153-60.

6 Hess RF, Holliday I. The spatial localisation deficit in human amblyopia. Vis Res 1992;32:1319-39.

7 Brock FW, Givner I. Fixation anomalies in amblyopia. Arch Ophthalmol 1952;47:775-86.

8 Burian HM, Cortimiglia R. Visual acuity and fixation pattern in patients with strabismic amblyopia. Am Orthop $\mathcal{F}$ 1962;12:169-72.

9 Buckley EG, Seaber JH. The incidence of strabismic amblyopia. Am f Orthop 1982;32:66-72.

10 Ciuffreda KJ, Kenyon RV, Stark L. Increased drift in amblyopic eyes. Br f Ophthalmol 1980;64:7-14.

11 Ching FC, Parks MM, Friendly DS. Practical management of amblyopia. F Pediatr Ophthalmol Strabismus 1986;23:917 .

12 Olson RJ, Scott WE. A practical approach to occlusion therapy for amblyopia. Sem Ophthamol 1997;12:161-5.

13 Von Noorden GK. In: Binocular vision and ocular motility: theory and management of strabismus. 5th ed. St Louis: CV Mosby 1996:512-20

14 Snowdon SK, Stewart-Brown SL. Pre-school screening: results of a systematic review. York: NHS Centre for Review and Dissemination. 1997. (CDR report 9. .)

15 Woodruff G, Hiscox F, Thompson JR, et al. Factors affecting the outcome of children treated for amblyopia. Eye 1994;8: 627-31.

16 Scott WE, Dickey CF. Stability of visual acuity in amblyopic patients after visual maturity. Graefes Arch Clin Exp Ophthalmol 1988;226:154-7.

17 Hiscox F, Strong N, Thompson JR, et al. Occlusion for amblyopia: a comprehensive survey of outcome. Eye 1992; 6:300-4.

18 Nucci P, Alfarano R, Piantanida A, et al. Compliance with antiamblyopia occlusion therapy. Acta Ophthalmol 1992;70: $128-31$

19 Leach C. Compliance with occlusion therapy for strabismic and anisometropic amblyopia: a pilot study. Binoc Vis Eye Muscle Surg 1995;10:257-66.

20 Fielder AR, Auld R, Irwin M, et al. Compliance monitoring in amblyopia therapy. Lancet 1994;343:547.

21 Fielder AR, Irwin M, Auld R, et al. Compliance in amblyopia therapy: objective monitoring of occlusion. $\mathrm{Br} f$ Ophthalmol 1995;79:585-9.

22 Moseley MJ, Fielder AR, Irwin M, et al. Effectiveness of occlusion therapy in ametropes: a pilot study. $\mathrm{Br} \mathcal{F}$ Ophthalmol 1997;81:956-61.

23 Lennerstrand G, Rydberg A. Results of treatment of amblyopia with a screening program for early detection. Acta Ophthalmol Scand 1996;74(Suppl 219):42-5.

24 Bowman RJC, Williamson TH, Andrews RGL, et al. An Bowman RJC, Williamson TH, Andrews RGL, et al. An
inner city preschool visual screening programme: long term inner city preschool visual screening programm
visual results. Br $\mathcal{F}$ Ophthalmol $1998 ; 82: 543-8$.

25 Haase W, Wenzel F. The natural course of untreated functional amblyopia: does it progress between childhood and adulthood? Binoc Vis Strab Qtly 1997;12:17-24.

26 Simons K, Preslan M. Natural history of amblyopia untreated owing to poor compliance. $B r \mathcal{F}$ Ophthalmol 1999;83:582-7.

27 Oliver M, Neumann R, Chaimoritch, et al. Compliance and results of treatment for amblyopia in children more than 8 years old. Am $\mathcal{F}$ Ophthalmol 1986;102:340-5.

28 Lithander J, Sjöstrand J. Anisometropic and strabismic amblyopia in the age group: a prospective study of the amblyopia in the age group: a prospective study of
effects of treament. Br f Ophthalmol 1991;75:111-16.

29 McGraw PV, Winn B. Glasgow acuity cards: a new test for the measurement of letter acuity. Ophthalmol Physiol Opt 1993;13:400-4. 
30 Simmers AJ, Gray LS, Spowart K. Screening for amblyopia: a comparison of paediatric letter tests. Br $\mathcal{F}$ Ophthalmol

31 McGraw PV. Studies of human macular function: developmental anomalies. PhD thesis. Scotland: Glasgow Caledonian University, 1995

32 Ciuffreda KJ, Levi DM, Selenow A. In: Amblyopia-basic and clinical aspects. Boston: Butterworth-Heinemann, 1991:354-5

33 Assaf AA. The sensitive period: transfer of fixation after occlusion for strabismic amblyopia. Br f Ophthalmol 1982, 66:64-7.

34 McGraw PV, Winn B, Whittaker D, et al. Positional acuity in amblyopia: does a perceptual consequence of neural recruitment exist? Ophthalmol Physiol Opt 1998;18:423-9.
35 Vaegan TD, Taylor DM. Critical period for deprivation amblyopia in children. Trans Ophthalmol Soc UK 1979;99: 432-49.

36 Epelbaum M, Milleret C, Buisseret P, et al. The sensitive period for strabismic amblyopia in humans. Ophthalmology 1993;3:323-7.

37 Ham O, Claramunt M, Diaz T. Strabismic amblyopia: final results of occlusion treatment in 205 cases. Binoc Vis 1986; 1:195-202.

38 Wertheim cited by Westheimer G. In: Hart WM Jr, ed. Adler's physiology of the eye. 9th ed. St Louis: CV Mosby, 1996:541.

39 Beardsell R, Clarke S, Hill M. Outcomes of occlusion treatment for amblyopia. F Pediatr Ophthalmol Strabismus 1999; 36:19-24. 